\title{
Non Habitual Immunotherapy by Using Irradiated Whole Tumor Cells
}

\begin{abstract}
Dalia M Mostafa*
National Center for Radiation Research and Technology (NCRRT), Atomic Energy Authority, Egypt
\end{abstract}

*Corresponding author: Dalia M Mostafa, National Center for Radiation Research and Technology (NCRRT), Atomic Energy Authority, Egypt, Tel: 01223425824; Email:

\section{Mini Review \\ Volume 3 Issue 1}

Received Date: April 14, 2020

Published Date: May 08, 2020

DOI: $10.23880 /$ ijnmrs-16000128 daliabadreldeen@outlook.com

\section{Abstract}

The objective of this article is to demonstrate that attenuating of viable whole tumor cells by $\gamma$-radiation and injecting them pre-tumor development is effective for enhancement of the immune system against tumor formation. The advantage of using $\gamma$-radiation is that the irradiated tumor cells remain viable but non-proliferative. The use of non-proliferative whole tumor cells vaccine in cancer immunotherapy isn't new but the new proposal is the immunization before tumor formation.

Keywords: Immunotherapy; Memory T Cells; CD8+ T Lymphocytes; Granzymes

Abbreviations: IFN- $\gamma$ : Interferon $\gamma$; PD-L1: Programmed Death Ligand 1; MHC: Major Histocompatibility Complex; APC: Antigen-Presenting Cells; TCR: T-Cell Receptor; KAR: Killer Activating Receptors; CLs: Cytotoxic Lymphocytes; FASL: Fas Ligand; TRAIL: TNF-Related Apoptosis Inducing Ligand; Gzms: Granzymes.

\section{Immune System Response for Immunization}

The advantage of using whole tumor cells as a vaccine instead of a specific protein or peptide tumor antigen is that the cells provide a source of all potential antigens, eliminating the need to identify the most favorable antigen to target in a specific type of cancer. In addition genetic instability of tumor cells often leads to the occurrence of a large number of mutations, and expression of nonsynonymous mutations can produce tumor-specific antigens called neoantigens. Neoantigens are highly immunogenic as they are not expressed in normal tissues [1]. Importantly, immune response to more than one tumor antigen is generated by targeting multiple tumor antigens at the same time [2] (Figures 1a \& 1b).

Identification of the tumor antigens is not necessary for tumor cell vaccine generation since the tumor cells contain the whole array of mutated epitopes for parallel presentation to both CD8+ and CD4+ T cells, which reduces the possibility of tumor escape [3], Moreover, tumor cell vaccines can induce interferon $\gamma$ (IFN- $\gamma$ ) secretion, which elicits the expression of programmed death ligand 1 (PD-L1) in the tumor and thus induces adaptive immune resistance [4].



Figure 1a: Solid tumor in thigh of one of the mice group injected with viable Ehrlich tumor cells $(n=15)$. 


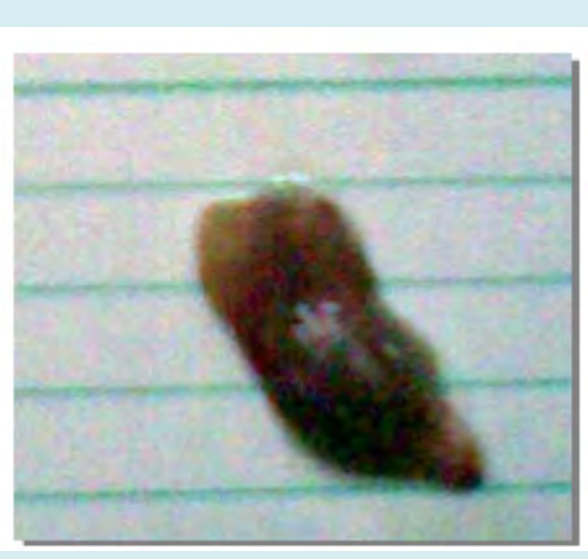

Figure 1b: Normal mice thigh from group of mice vaccinated with irradiated tumor cells before challenge with viable Ehrlich tumor cells $(n=15$, no tumor formation in the entire group).
Effective immunization induces the development of populations of robust effector lymphocytes specific for the immunizing antigens. Among them are cytotoxic (CD8+) T lymphocytes, which differentiate into long-lived memory cells persisting in the host and exhibiting improved functional characteristics. Memory cells can confer rapid host protection upon antigen-mediated activation and causes direct killing of infected cells [5].

\section{Formation of memory T cells}

Upon exposure to a foreign antigen, antigen-specific $\mathrm{T}$ cells proliferate and differentiate into effectors that eliminate the foreign intruder. The vast majority of effector $\mathrm{T}$ cells, however, undergo apoptosis as the immune response progresses and the few lymphocytes that survive become long-lived memory $\mathrm{T}$ cells $[6,7]$. Memory $\mathrm{T}$ cells recognize antigens and provide the organism with long-lasting protection [8] (Figure 2).

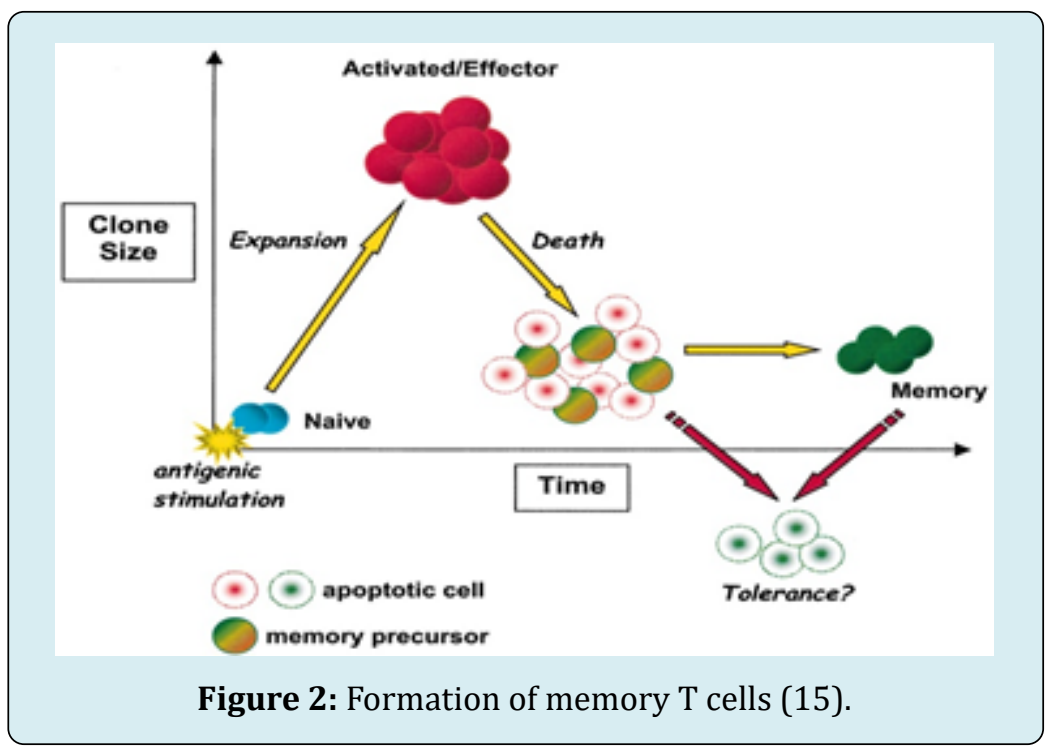

Memory T cells have over their naïve counterparts several inherent advantages. The first advantage that their response to a foreign antigen is greater in magnitude and faster than that of naïve $\mathrm{T}$ cell response. Memory $\mathrm{T}$ cells generate $\mathrm{a}$ considerable number of effector T cells, capable of cytokine secretion and/or cytolytic activity, within hours of antigenic restimulation, whereas naïve $\mathrm{T}$ cells generate a smaller number of effectors and at a much slower pace (days) $[9,10]$. Second, antigen-specific memory $\mathrm{T}$ cell populations persist for years to a lifetime in humans, and their survival seems to be antigen and MHC (major histocompatibility complex) independent $[11,12]$. Mature naïve $\mathrm{T}$ cell populations also persist for a relatively long period of time (months to a few years in humans), but their survival is dependent on constant, low-grade stimulation with MHC-self- peptide complexes $[13,14]$. Third, the circulation of naïve $\mathrm{T}$ cells is restricted to secondary lymphoid tissues (spleen, lymph nodes, and mucosa-associated lymphoid tissues), the site where they are activated by foreign antigens presented by antigen-presenting cells (APC), whereas memory $\mathrm{T}$ cells circulate through both secondary lymphoid tissues and peripheral nonlymphoid tissues $[15,16]$.

Unlike naïve $\mathrm{T}$ cells, memory $\mathrm{T}$ cells can directly encounter foreign antigen and mount a productive immune response within nonlymphoid tissues [14]. The migratory advantage of memory $\mathrm{T}$ cells, therefore, allows them to detect and eliminate a foreign intruder long before it reaches secondary lymphoid tissues [17]. Despite this rapid replacement of memory $\mathrm{T}$ cells by new naive $\mathrm{T}$ cells, around 
$50 \%$ of the pool of memory $\mathrm{T}$ cells that had formed before was never replaced by new naive $\mathrm{T}$ cells. Thus, although a substantial fraction of the memory T-cell pool is replaced at high rates throughout life, an equally large proportion is kept from an early age [18].

\section{Killing mechanism of CD8+ T lymphocytes (Cytotoxic Lymphocytes)}

Stimulation through the T-cell receptor (TCR) or through killer activating receptors (KAR) induces the activation of effector mechanisms by cytotoxic lymphocytes (CLs), including expression and release of death ligands like FasL (Fas ligand) and TRAIL (TNF-related apoptosis inducing ligand) $[19,20]$ and the granule exocytosis pathway.
The granule exocytosis pathway is rapidly achieved by a directional mobilization of specialized cytoplasmic granules, toward the contact site of CLs and target cells (the immunological synapse), where their contents are released, $[21,22]$ which are the pore forming protein, perforin [23], along with granzymes (GZMs), which are members of a family of serine proteases and are the dominant constituents of the catalytic granules $[24,25]$. GZMs deliver into the cytosol of the target cell [23]. Once released in the cytosol, GZMs would execute the target cells by cleaving critical intracellular substrates controlling cell death and survival [26]. The main role of FasL and TRAIL seems to be associated with the control of T-cell homeostasis by a process known as activation-induced cell death even though their contribution to CL-mediated cell death and tumor immunosurveillance is less clear [27] (Figure 3).

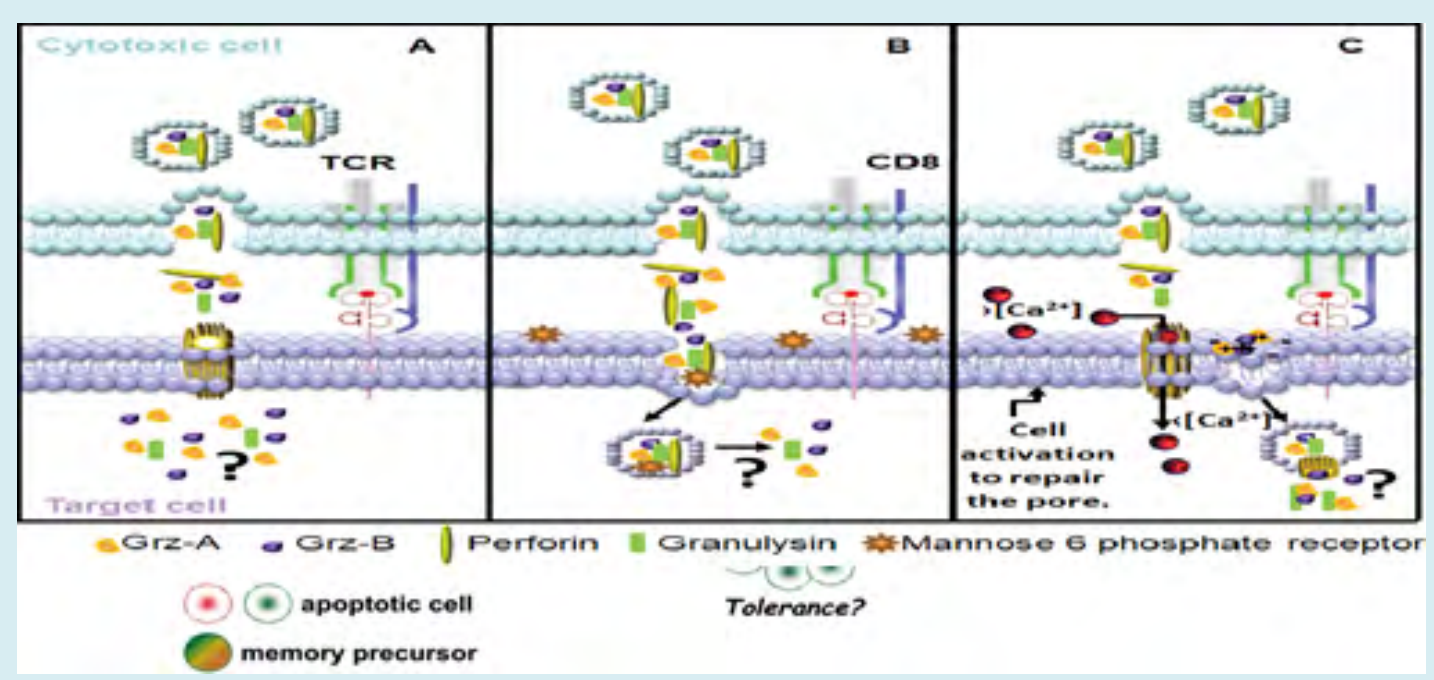

Figure 3: Three proposed models for internalization of lytic molecules. (A) Perforin polymerizes on the target cell membrane forming a pore through which granzymes (Grz)-A, -B, and granulysin enter to induce apoptosis. (B) The target cell membrane expresses mannose-6-phosphate receptor that forms a complex with Grz-B, which is then internalized together with Grz-A and granulysin inside vesicles and released by pore-forming perforin into the cytoplasm, where these molecules exert their function. (C) The pore formed by perforin allows the entry of extracellular Ca2+ activating the target cell, which attempts to repair the damage and endocytoses the membrane region together with lytic molecules adhered by electrostatic linkages [28].

\section{Conclusion}

It was observed that the use of irradiated tumor cells as a vaccine against challenge with the same tumor line enhances the immune system to prevent tumor formation or delays tumor recurrence and prolongs survival compared to surgery, chemotherapy and radiotherapy. This needs more studies in order to determine whether the irradiated tumor cells vaccine has the potential to provide effective, longlasting antitumor immunity.

\section{References}

1. Peng M, Mo Y, Wang Y, Wu P, Zhang Y, et al. (2019) Neoantigen vaccine: an emerging tumor immunotherapy. Molecular Cancer 18: 128.

2. Keenana BP, Jaffeeb EM (2012) Whole Cell Vaccines-Past Progress and Future Strategies. Semin Oncol 39(3): 276286.

3. Chiang CLL, Benencia F, Coukos G (2010) Whole tumor antigen vaccines. Semin Immunol 22(3): 132-143. 
4. Okazaki T, Honjo T (2006) The PD-1-PD-L pathway in immunological tolerance. Trends Immunol 27(4): 195201.

5. Lauvau G, Soudja SM'H (2015) Mechanism of memory T cell activation and effective immunity. Adv Exp Med Biol 850: 73-80.

6. Kaech SM, Wherry EJ, Ahmed R (2002) Effector and memory $\mathrm{T}$ cell differentiation: Implications for vaccine development. Nat Rev Immunol 2(4): 251-262.

7. Sprent J, Surh CD (2002) T cell memory. Annu Rev Immunol 20: 551-579.

8. Heeger PS, Greenspan NS, Kuhlenschmidt S, Dejelo C, Hricik DE, et al. (1999) Pretransplant frequency of donorspecific, IFN-producing lymphocytes is a manifestation of immunologic memory and correlates with the risk of post- transplant rejection episodes. J Immunol 163(4): 2267-2275.

9. Rogers PR, Dubey C, Swain SL (2000) Qualitative changes accompany memory $\mathrm{T}$ cell generation: Faster, more effective responses at lower doses of antigen. J Immunol 164(5): 2338-2346.

10. Veiga-Fernandes $H$, Walter U, Bourgeois C, McLean A, Rocha B (2000) Response of naive and memory CD8+ T cells to antigen stimulation in vivo. Nat Immunol 1(1): 47-53.

11. Mullbacher A (1994) The long-term maintenance of cytotoxic T cell memory does not require persistence of antigen. J Exp Med 179(1): 317-321.

12. Swain SL, Hu H, Huston G (1999) Class II-independent generation of CD4 memory T cells from effectors. Science 286(5443): 1381-1383.

13. Takeda S, Rodewald HR, Arakawa H, Bluethmann H, Shimizu T (1996) MHC class II molecules are not required for survival of newly generated CD4 T cells, but affect their long-term life span. Immunity 5(3): 217-228.

14. Dai Z, Lakkis FG (2001) Cutting edge: Secondary lymphoid organs are necessary for maintaining the CD4, but not CD8, naive T cell pool. J Immunol 167(12): 67116715.

15. Reinhardt RL, Khoruts A, Merica R, Zell T, Jenkins MK (2001) Visualizing the generation of memory CD4 T cells in the whole body. Nature 410(6824): 101-105.

16. Chalasani G, Dai Z, Konieczny BT, Baddoura FK, Lakkis FG (2002) Recall and propagation of allospecific memory $T$ cells independent of secondary lymphoid organs. Proc Natl Acad Sci USA 99(9): 6175-6180.
17. Lakkis FG, Sayegh MH (2003) Memory T Cells: A Hurdle to Immunologic Tolerance. J Am Soc Nephrol 14(9): 2402-2410.

18. Borghans J, Ribeiro RM (2017) T-cell immunology: The maths of memory. eLife 6: 26754.

19. Takeda K, Hayakawa Y, Smyth MJ, Kayagaki N, Yamaguchi $\mathrm{N}$, et al. (2001) Involvement of tumor necrosis factorrelated apoptosis-inducing ligand in surveillance of tumor metastasis by liver natural killer cells. Nat Med 7(1): 94-100.

20. Anel A, Buferne M, Boyer C, Schmitt-Verhulst AM, Golstein P (1994) T cell receptor-induced Fas ligand expression in cytotoxic T lymphocyte clones is blocked by protein tyrosine kinase inhibitors and cyclosporin $\mathrm{A}$. Eur J Immunol 24: 2469-2476.

21. Bossi G, Griffiths GM (2005) CTL secretory lysosomes: biogenesis and secretion of a harmful organelle. Semin Immunol 17(1): 87-94.

22. de Saint Basile G, Menasche G, Fischer A (2010) Molecular mechanisms of biogenesis and exocytosis of cytotoxic granules. Nat Rev Immunol 10(8): 568-579.

23. Voskoboinik I, Smyth MJ, Trapani JA (2006) Perforinmediated target-cell death and immune homeostasis. Nat Rev Immunol 6(12): 940-952.

24. Pardo J, Aguilo JI, Anel A, Martin P, Joeckel L, et al. (2009) The biology of cytotoxic cell granule exocytosis pathway: granzymes have evolved to induce cell death and inflammation. Microbes Infect 11(4): 452-459.

25. Chowdhury D, Lieberman J (2008) Death by a thousand cuts: granzyme pathways of programmed cell death. Annu Rev Immunol 26: 389-420.

26. Andrade F (2010) Non-cytotoxic antiviral activities of granzymes in the context of the immune antiviral state. Immunol Rev 235(1): 128-146.

27. Martínez-Lostao L, Ane A, Pardo J (2015) How Do Cytotoxic Lymphocytes Kill Cancer Cells?. Clin Cancer Res 21(22): 5047-5056.

28. Chávez-Galán L, Arenas-Del Angel MC, Zenteno E, Chávez R, Lascurain R (2009) Cell Death Mechanisms Induced by Cytotoxic Lymphocytes. Cell Mol Immunol 6(1): 1525. 